\title{
An interactive map of Tunisian toponymy.
}

\author{
Mohsen DHIEB ${ }^{\mathrm{a} *}$ Kamel NASRAOUI $^{\mathrm{b}}$ \\ ${ }^{\mathrm{a}}$ University of Sfax-Faculty of Arts and Humanities - Department of Geography-Laboratory SYFACTE-GEOMAGE \\ Mohsendhieb2003@yahoo.fr \\ ${ }^{\mathrm{b}}$ University of Sfax-Faculty of Arts and Humanities - Department of Geography-Laboratory SYFACTE-GEOMAGE \\ Mohsendhieb2003@yahoo.fr
}

\section{* Corresponding author: Mohsen DHIEB}

Keywords: Graphics Design- Semiology of Graphics- Bertin's rules - Urban Atlas of Jeddah.

\begin{abstract}
:
Toponyms are living bodies that evolve continuously over time. When studying the present toponymic items of one region, many factors intervene to determine their genesis, their origin, their present use and their recent evolution.

Portraying the Tunisian toponymic landscape with its various characteristics should address such issues for specialists and for common users. It is important first, to bring altogether the various toponyms of one place in one chosen language, and second to give insights on such characteristics of each toponym altogether. This should be done by an Interactive Toponymistic Map of Tunisia (ITM).
\end{abstract}

The goals of this research are first, to make an inventory of the Tunisian most used toponyms; second to classify them through the most known historical periods and their various transcriptions; and third to show the evolution of the overall Tunisian toponymic landscape in one sight by using an ITM. 